\title{
Enzymatic Hydrophobic Modification of Jute Fibers via Grafting to Reinforce Composites
}

\author{
Ruirui Liu $^{1}$ - Aixue Dong ${ }^{1} \cdot$ Xuerong Fan ${ }^{1,2}$ • \\ Yuanyuan Yu ${ }^{1} \cdot$ Jiugang Yuan $^{1,2} \cdot$ Ping Wang $^{1}$ • \\ Qiang Wang ${ }^{1,2} \cdot$ Artur Cavaco-Paulo ${ }^{2,3}$
}

Received: 12 October 2015 / Accepted: 28 December 2015 /

Published online: 11 January 2016

(C) Springer Science+Business Media New York 2016

\begin{abstract}
Horseradish peroxidase (HRP) $/ \mathrm{H}_{2} \mathrm{O}_{2}$ system catalyzes the free-radical polymerization of aromatic compounds such as lignins and gallate esters. In this work, dodecyl gallate (DG) was grafted onto the surfaces of lignin-rich jute fabrics by HRP-mediated oxidative polymerization with an aim to enhance the hydrophobicity of the fibers. The DG-grafted jute fibers and reaction products of their model compounds were characterized by matrix-assisted laser desorption/ionization mass spectrometry (MALDI-TOF MS), attenuated total reflection Fourier transform infrared spectroscopy (ATR-FTIR), X-ray photoelectron spectroscopy (XPS), scanning electron microscopy (SEM), thermogravimetric analysis (TGA), and differential scanning calorimetry (DSC). The results clearly indicated the grafting of DG to the jute fiber by HRP. Furthermore, the hydrophobicity of jute fabrics was determined by measuring the wetting time and static contact angle. Compared to the control sample, the wetting time and static contact angle of the grated fabrics changed from $\sim 1 \mathrm{~s}$ to $1 \mathrm{~h}$ and from $\sim 0^{\circ}$ to $123.68^{\circ}$, respectively. This clearly proved that the hydrophobicity of jute fabrics improved considerably. Conditions of the HRP-catalyzed DG-grafting reactions were optimized in terms of the DG content of modified jute fabrics. Moreover, the results of breaking strength and elongation of DG-grafted jute/ polypropylene (PP) composites demonstrated improved reinforcement of the composite due to enzymatic hydrophobic modification of jute fibers.
\end{abstract}

Qiang Wang

qiang_wang@163.com

1 Key Laboratory of Science and Technology of Eco-Textile, Ministry of Education, Jiangnan University, Wuxi 214122 Jiangsu, China

2 International Joint Research Laboratory for Textile and Fiber Bioprocesses, Jiangnan University, Wuxi 214122 Jiangsu, China

3 Department of Biological Engineering, University of Minho, Campus de Gualtar, 4710-057 Braga, Portugal 
Keywords Enzyme biocatalysis $\cdot$ Hydrophobicity $\cdot$ Lignin $\cdot$ Composite $\cdot$ Heterogeneous biocatalysis $\cdot$ Horseradish peroxidase

\section{Introduction}

In view of the increased environmental awareness and conscious efforts to protect the environment, the development of fully green composites (consisting of a biodegradable polymer matrix and natural fibers) with high performance, has become one of the hottest research areas in the world [1-3]. At present, investigations into the application of some natural fibers [4-6], especially lignocellulosics like jute fibers [7-9], as the fiber-reinforced material in composites are increasing due to their low density, low cost, high strength, and environmentally friendly nature.

However, most of the natural fibers cannot be compatibilized with hydrophobic resins, owing to their highly polar and hydrophilic nature. This reduces the mechanical properties of composites significantly [10]. In order to improve the adhesion or bonding between fibers and resins, physical [11-14] and chemical [15-17] processing technologies have been employed, which involve modification of the natural fibers. It should be noted that these methods still have some inherent shortcomings, like severe damage caused to fibers during treatment, which limit the application of natural fibers in composites.

In recent years, biological processing of lignocellulosic materials shows great potential as a candidate to replace conventional treatments due to its superior features, such as specificity, high-efficiency, and milder conditions. For instance, horseradish peroxidase (HRP, EC1.11.1.7), a plant peroxidase obtained from the roots of horseradish, can catalyze the one-electron oxidation of a wide variety of hydrogen donors, such as aromatic compounds and even reactive radicals, in a redox reaction, in the presence of hydrogen peroxide $\left(\mathrm{H}_{2} \mathrm{O}_{2}\right)$ [18-20]. Lignin, a complex three-dimensional amorphous polymer, consisting of $p$-hydroxyphenyl $(\mathrm{H})$, guaiacyl $(\mathrm{G})$, and syringyl $(\mathrm{S})$ units [21], is a suitable substrate for HRP oxidation. The enzymatic reaction between lignin and phenols [22] or poly (Nisopropylacrylamide) (PNIPAM) [23] has been reported previously. Considering that jute fiber contains 13.3-16.1\% lignin [21], HRP-catalyzed grafting of hydrophobic molecules onto the surface of jute fibers provides a new approach, by which the hydrophobic character of jute fibers increases and they become compatible with the hydrophobic resins.

In this work, dodecyl gallate (DG) with hydrophobic groups was enzymatically grafted onto the lignin-rich jute fabric surface by HRP, as illustrated in Fig. 1. The grafted products were characterized by matrix-assisted laser desorption/ionization mass spectrometry (MALDI-TOF MS), attenuated total reflection Fourier transform infrared spectroscopy (ATR-FTIR), X-ray photoelectron spectroscopy (XPS), scanning electron microscopy (SEM), thermogravimetric analysis (TGA), and differential scanning calorimetry (DSC). The modified jute fibers, endowed with hydrophobicity, were used as the reinforced materials for the resin matrix composites and the mechanical properties, such as breaking strength and elongation of DG-grafted jute/polypropylene (PP) composites were assessed. 


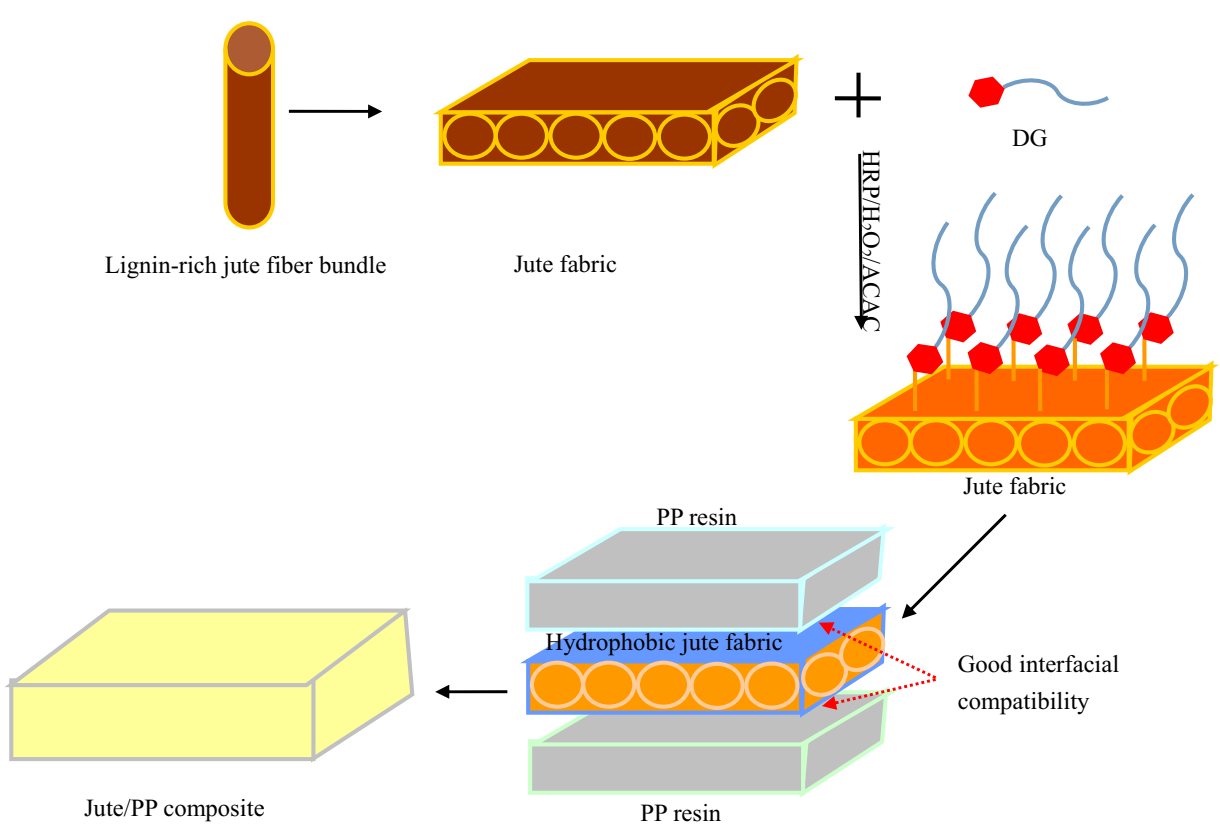

Fig. 1 Schematic illustration of HRP-catalyzed grafting reaction of dodecyl gallate (DG) onto the jute fabric

\section{Experimental}

\section{Materials and Reagents}

The $100 \%$ raw jute fabric, with a $7 / 7$ (warp/weft) $\mathrm{cm}^{-1}$ yarn count, was supplied by Longtai Weaving Company (Changshu, China). Horseradish peroxidase (332 U/mg), stored at $-20{ }^{\circ} \mathrm{C}$, was purchased from Aladdin Reagent Co., Ltd. (Shanghai, China). PP spunlace non-woven cloth was provided by Yonghui Textile Technology Co., Ltd. (Yangzhou, China). DG with $98 \%$ purity was supplied by J\&K Technology Co., Ltd. (Beijing, China). 4-Propylguaiacol (2-methoxy-4-propylphenol, MP) was purchased from Sigma-Aldrich Co. LLC. Propyl gallate (PG) was provided by Shanghai Shifeng Biological Technology Co. Ltd. (Shanghai, China). All the other chemicals used in this study were commercially available and of analytical grade.

\section{Pretreatment of Jute Fabrics}

The jute fabrics were Soxhlet-extracted with benzene/ethanol $(v / v, 2: 1)$ for $12 \mathrm{~h}$ to eliminate organic impurities on the fabric surface. These impurities include lipophilic extractives, which may interfere with the oxidation of substrate molecules, thereby affecting the analysis of modified surfaces. Then, jute fabrics were immersed in boiling deionized water for $3 \mathrm{~h}$ to remove the starch or polyvinyl alcohol (PVA) sizes. Then, iodine-potassium iodide method was used to ensure the complete removal of all the sizes. After these treatments, more lignin components were exposed on the surface of jute fibers. 


\section{HRP-mediated Grafting Reaction of Model Compounds}

The lignin model compound (2-methoxy-4-propylphenol, MP, $0.2 \mathrm{~mL}$ ), $0.1 \mathrm{~g}$ of PG, $3.0 \mathrm{~mL}$ of ethanol, $0.1 \mathrm{~mL}$ of acetylacetone (ACAC), and $0.1 \mathrm{~mL}$ HRP $(1 \mathrm{mg} / \mathrm{mL}$ ) were taken in a $100-\mathrm{mL}$ three-necked round-bottom flask. Then, a certain volume of phosphate buffer $(0.1 \mathrm{M}, \mathrm{pH}$ 7.0) was added to the flask, taking the volume of reaction solution to $30 \mathrm{~mL}$. The reaction mixture was degassed for $30 \mathrm{~min}$, followed by addition of $0.1 \mathrm{~mL} \mathrm{H} \mathrm{H}_{2}(30 \mathrm{wt} \%)$ to initiate the reaction. It was then maintained at $30{ }^{\circ} \mathrm{C}$ for $2.5 \mathrm{~h}$. The constituents of the products were analyzed by MALDI-TOF MS. Other samples, treated with either MP alone or PG alone, followed the same treatment conditions, as mentioned above.

\section{HRP-Mediated Grafting of DG onto Jute Fiber Surfaces}

One gram of jute fabrics was placed in a $250-\mathrm{mL}$ three-necked round-bottom flask, which contained $50 \mathrm{~mL}$ of reaction mixture, which included $10 \mathrm{mmol} / \mathrm{L}$ of DG, $15 \%$ $(v / v)$ of ethanol, $0.5 \mathrm{~mL}$ of ACAC, $1.0 \mathrm{~mL}$ of HRP $(1 \mathrm{mg} / \mathrm{mL})$, and a certain volume of phosphate buffer $(0.1 \mathrm{M}, \mathrm{pH} 7.0)$. The entire reaction mixture was degassed for $30 \mathrm{~min}$. Then, $0.75 \mathrm{~mL}$ of $\mathrm{H}_{2} \mathrm{O}_{2}(30 \mathrm{wt} \%)$ was added drop-wise. After the addition, the reaction was maintained at $50{ }^{\circ} \mathrm{C}$ for $4 \mathrm{~h}$. The resulting sample was washed twice with a certain volume of ethanol and deionized water to eliminate the DG homopolymer and HRP adsorbed on the jute surface, respectively. It was further extracted with acetone for $12 \mathrm{~h}$ to remove the absorbed DG, ACAC, and the homooligomers of the monomers. The other samples followed the same treatment conditions as the HRP treatment [7].

It should be noted that other alcohol-soluble and hydrophobic monomers such as cardanol could theoretically be used for the hydrophobic modification of jute fibers. In this work, we merely focused on the grafting of DG on jute fabrics.

\section{MALDI-TOF MS Analysis}

Formations of heterocompounds between the modifying chemicals (PG, the model compound of DG) and lignin model compound (MP) treated with different chemicals were studied using a Bruker ultrafleXtreme MALDI-TOF/TOF MS (Bremen and Leipzig, Germany).

For the MALDI-TOF MS analysis, the precipitates and reaction solutions were dissolved in $\mathrm{N}, \mathrm{N}$-dimethyl formamide (DMF). A 2- $\mu \mathrm{L}$ DMF solution of the precipitate/reaction mixture in a $1: 1$ ratio $(v / v)$ along with matrix $(2,5-$ dihydroxybenzoic acid, DHB) was dried on the MALDI target plate at room temperature. DHB solution was prepared by dissolving 20-mg DHB in $1 \mathrm{~mL}$ of water containing $10 \%$ ethanol and $1 \mathrm{mM} \mathrm{NaCl}$ solution. The positive ion mass spectra were acquired from the dried sample spots in reflector mode. Data collection and processing were carried out using flexControl and flexAnalysis version 3.3. The Bruker Proflex instrument was equipped with a nitrogen laser (Smartbeam II, modified Nd: YAG laser) with a 337-nm wavelength. 


\section{Characterization of Jute Fabric Surface}

\section{FTIR Analysis}

The attenuated-total-reflection Fourier transform infrared (ATR-FTIR) spectra of jute fabrics were recorded using a Nicolet iS10 FTIR spectrometer (Thermo Fisher Scientific, USA) attached to an ATR apparatus. Thirty-two scans per sample were obtained in the spectral range of $650-4000 \mathrm{~cm}^{-1}$ at a resolution of $4 \mathrm{~cm}^{-1}$.

\section{XPS Analysis}

XPS was performed at the Laboratory of Surface Chemistry, Fudan University (Shanghai, China) to assess the binding of DG, according to the method of Dong et al. [7].

\section{SEM Analysis}

SEM (SU1510, Hitachi, Japan) was employed to obtain the micrographs of the jute fibers under $5.00 \mathrm{kV}$ at a magnification of $3.00 \mathrm{k}$ to study their morphologies. The surface of jute fiber was coated with gold by vacuum evaporation.

\section{Thermal Analysis}

\section{TGA Analysis}

TGA was conducted on a TGA/Q500 thermoanalysis system (TA Instruments, USA) in the temperature range of $30-700{ }^{\circ} \mathrm{C}$ at a heating rate of $20{ }^{\circ} \mathrm{C} / \mathrm{min}$.

\section{DSC Analysis}

DSC analysis of the jute samples was carried out using a Q200 DSC (TA Instruments). The curves were recorded in the temperature range of $30-400{ }^{\circ} \mathrm{C}$ at a heating rate of $20{ }^{\circ} \mathrm{C} / \mathrm{min}$.

\section{Determination of GP}

The untreated and DG-grafted jute fabrics were quantitatively titrated with hydrochloric acid after saponification of the ester groups by alkali. One gram of jute fabric was cut into pieces and incubated in $50 \mathrm{~mL}$ of $0.1 \mathrm{M} \mathrm{NaOH}$ solution at $90{ }^{\circ} \mathrm{C}$ for $2 \mathrm{~h}$. The excess $\mathrm{NaOH}$ was titrated against $0.1 \mathrm{M} \mathrm{HCl}$ solution using a WDDY-2008 J automatic potentiometric titrator. Triplicate samples were measured for each treatment and the results were averaged.

The DG content of the modified jute fabric was determined as the relative molar percentage of the ester groups regarding the hydroxyl groups consumed according to the following equation:

$$
\text { DGcontent }(\%)=\frac{\left[V_{H C l}(\text { control })-V_{H C l}(\text { sample })\right] \times C_{H C l} \times M_{C_{19} H_{30} O_{5}}}{3} \times 100
$$


where, $V_{\mathrm{HCl}}$ is the volume of $\mathrm{HCl}$ consumed (L), $C$ is the molar concentration of $\mathrm{HCl}$ $(\mathrm{mol} / \mathrm{L})$, and $M$ is the molar mass of dodecyl gallate $(\mathrm{g} / \mathrm{mol})$.

The grafting percentage (GP) was calculated according the following equation:

$$
G P(\%)=\frac{w}{1-w} \times 100
$$

where $w$ is the DG content on the modified jute fabric.

\section{Optimization of Enzymatic Grafting}

The enzymatic conditions including dosages of DG (4-14 mmol/L), ethanol $(5-30 \%, v / v)$, HRP $(0.25-1.5 \mathrm{~mL})$, and $\mathrm{H}_{2} \mathrm{O}_{2}(0.25-1.5 \mathrm{~mL})$, incubation temperatures $\left(30-80{ }^{\circ} \mathrm{C}\right)$, and incubation periods $(2-10 \mathrm{~h})$ were optimized. Grafting was expressed in terms of the GP as mentioned above.

\section{Hydrophobicity Measurement}

The hydrophobicity of jute samples was evaluated by the wetting time and water contact angle measurements, according to the literature method [24].

\section{Preparation of Jute Fabric/PP Composites}

Jute fabric/PP composites were prepared using a PP spunlace non-woven cloth and jute fabrics as raw materials by a hot pressing method. First, the jute fabrics were cut into pieces, each having dimensions of $10 \times 2 \mathrm{~cm}^{2}$. Then, the composite samples were prepared by successively laying two layers of jute fabrics and three layers of PP cloth in a mass ratio of 2:1. Finally, the composite samples were compressed in a mould at $180{ }^{\circ} \mathrm{C}$ under 4-t pressure for $5 \mathrm{~min}$, and then they were taken out after cooling at room temperature without the applied pressure for $50 \mathrm{~min}$.

\section{Evaluation of Mechanical Properties of Jute Fabric/PP Composites}

The breaking strength of the jute fabric/PP composite sample was determined using a microcomputer-controlled electronic universal testing machine (KD111-5 model), operating at a constant speed $10 \mathrm{~mm} / \mathrm{min}$. A computerized stress-strain curve of the composite was obtained, and the data for the breaking strength and elongation were recorded. Five specimens were measured per treatment and the results were averaged.

\section{Results and Discussion}

\section{MALDI-TOF MS Analysis}

The hypothetical mechanism of propyl gallate and 4-propylguaiacol polymerization catalyzed by HRP is shown in Fig. 2. Reaction of MP (a model compound of lignin) 
<smiles>CC(=O)CC(C)C(C)C(C)=O</smiles><smiles>CCCOC(=O)c1cc(O)c(O)c(C(=O)OCCC)c1</smiles><smiles>CCCc1ccc(O)c(OC)c1</smiles><smiles>CCCC1=CCC(=O)C(OC)=C1</smiles><smiles>CCCOc1cc(CCC)cc(Oc2cc(C(=O)OCC)cc(O)c2O)c1O</smiles>

Fig. 2 Hypothetical mechanism of propyl gallate and 4-propylguaiacol polymerization catalyzed by HRP

with gallate molecule, with the formation of covalent bonds, demonstrates that gallate can be grafted onto lignin, which is present in the jute fibers. Furthermore, PG was selected as a model compound for DG, as it was easy to dissolve in hot water. The detailed structural information of the polymers formed from PG and MP by HRP was investigated and analyzed using MALDI-TOF MS (Fig. 3). Arrows indicate a mass difference of $164 \mathrm{Da}$ for the polymer formed from MP. The $\mathrm{m} / \mathrm{z}$ values of the polymerizates that were predicted and also determined were $\mathrm{m} / \mathrm{z} 377.29,558.17$, 603.77, and 727.00, which contained 1 to 2 units of PG and 1 to 3 units of MP and are shown in Table 1 . The results corresponded directly to laccase-mediated polymerization reactions of phenolic compounds, such as lignans and lignin model compounds [25, 26], and oxidative polymerization of phenols and polyphenols by HRP and laccase [27]. From the above results, the successful polymerization of PG and MP can be demonstrated and grafting of DG onto lignins present on the surface of the jute fibers could be inferred. 
Fig. 3 Expanded section of MALDI-TOF mass spectra of polymers. a 4-propylguaiacol (MP), b propyl gallate (PG), and c MP-PG

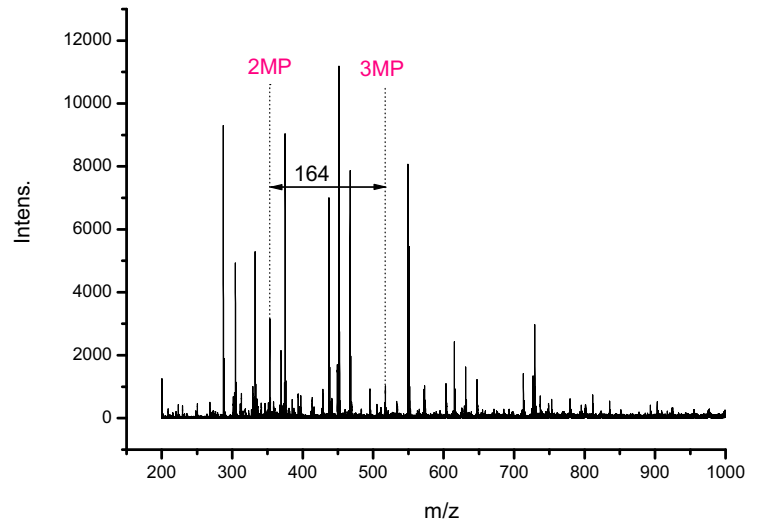

(a)

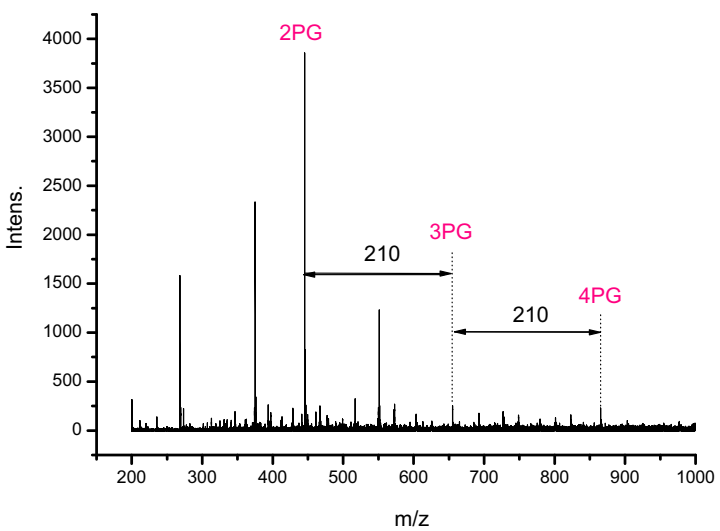

(b)

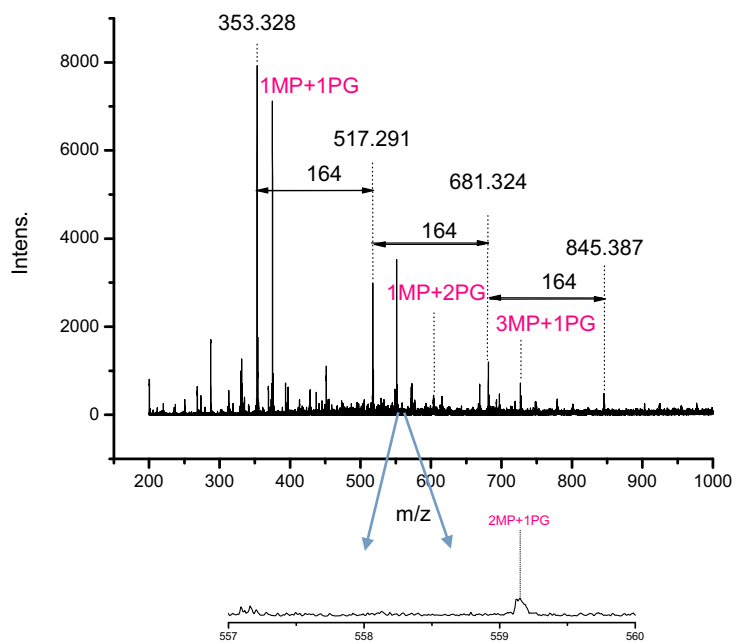

(c) 
Table 1 The m/z of MALDI-TOF mass spectrum of the polymers of 4-propylguaiacol (MP) and propyl gallate (PG)

\begin{tabular}{lllll}
\hline Sample & Compound & Predicted m/z (Da) & Detected m/z (Da) & $\Delta \mathrm{m} / \mathrm{z}(\mathrm{Da})$ \\
\hline Polymers of MP (Fig. 3a) & $(\mathrm{MP})_{2} \mathrm{H}^{+}$ & 331.40 & 331.23 & 0.17 \\
& $(\mathrm{MP})_{2} \mathrm{OH}^{+}$ & 347.40 & 346.47 & 0.93 \\
& $(\mathrm{MP})_{2} \mathrm{Na}^{+}$ & 353.39 & 353.33 & 0.06 \\
& $(\mathrm{MP})_{2} \mathrm{O} \mathrm{Na}^{+}$ & 369.39 & 369.31 & 0.08 \\
& $(\mathrm{MP})_{3} \mathrm{H}^{+}$ & 495.66 & 495.28 & 0.38 \\
& $(\mathrm{MP})_{3} \mathrm{Na}^{+}$ & 517.65 & 517.30 & 0.35 \\
Polymers of MP and PG (Fig. 3c) & $\left.(\mathrm{MP})_{3} \mathrm{O} \mathrm{Na}\right)_{1}\left(\mathrm{PG}_{1} \mathrm{H}^{+}\right.$ & 533.65 & 533.28 & 0.37 \\
& $(\mathrm{MP})_{1}\left(\mathrm{PG}_{2} \mathrm{OH}^{+}\right.$ & 603.62 & 377.13 & 0.15 \\
& $(\mathrm{MP})_{2}\left(\mathrm{PG}_{1} \mathrm{OH}^{+}\right.$ & 557.64 & 603.77 & -0.15 \\
& $(\mathrm{MP})_{3}\left({\mathrm{PG})_{1} \mathrm{Na}^{+}}\right.$ & 727.85 & 558.17 & -0.53 \\
& $(\mathrm{PG})_{2} \mathrm{Na}^{+}$ & 445.14 & 727.00 & 0.85 \\
Polymers of PG (Fig. 3b) & $(\mathrm{PG})_{2} \mathrm{ONa}^{+}$ & 461.14 & 445.18 & -0.04 \\
& $(\mathrm{PG})_{3} \mathrm{Na}^{+}$ & 655.20 & 461.16 & -0.02 \\
& $(\mathrm{PG})_{4} \mathrm{Na}^{+}$ & 865.27 & 655.14 & 0.06 \\
\hline
\end{tabular}

\section{FTIR Analysis of Jute Fabrics}

ATR-IR was used to demonstrate that jute fiber was chemically altered by reaction with HRP. Figure 4 shows a comparison of the ATR-IR spectra for the DG alone-treated and grafted jute fabric samples. Compared to the DG alone-treated sample, the grafted jute showed increased absorption of the $\mathrm{O}-\mathrm{H}$ stretching vibration $\left(3340 \mathrm{~cm}^{-1}\right), \mathrm{C}=\mathrm{O}$ stretching vibrations (1730 and

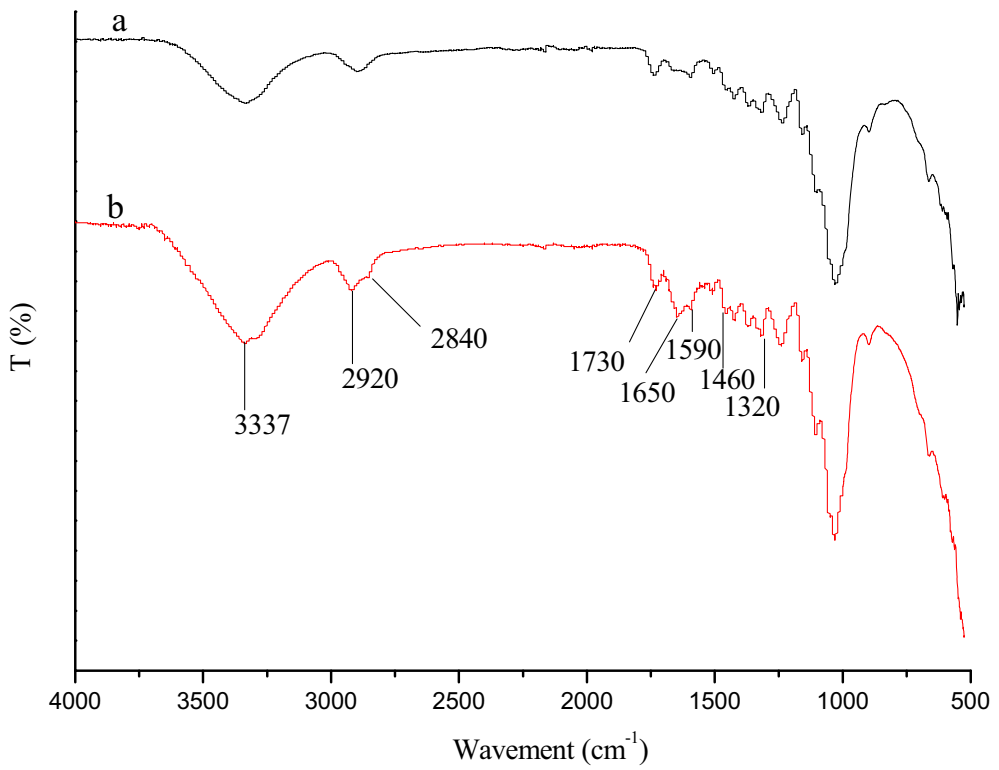

Fig. 4 FTIR spectra of the DG alone-treated (a) and grafted (b) jute fabric sample 
$1650 \mathrm{~cm}^{-1}$ ), and the aromatic skeletal vibrations (1590 and $\left.1460 \mathrm{~cm}^{-1}\right)$. Cellulose, hemicellulose, and lignin were the only main components, because wax and pectin had been removed after the pretreatment. It is well known that the hydroxyl groups and the saturated $\mathrm{C}-\mathrm{H}$ bonds were well distributed in cellulose, hemicellulose, and lignin, whereas only the carbonyl group was derived from lignin [28]. Therefore, an increase in the vibrations mentioned above was an indication of the transformation of lignin by HRP. In contrast to the DG alone-treated sample, the grafted jute also showed a slight enhancement of peak corresponding to the $-\mathrm{CH}_{2}-$ bending vibration at $1320 \mathrm{~cm}^{-1}$. The structure of DG molecular, shown in Fig. 2c, contains hydroxyl group, carbonyl group, phenyl group, and also a long methylene chain. Similar to the grafting of gallates onto chitosan $[29,30]$, two new peaks corresponding to the saturated $\mathrm{C}-\mathrm{H}$ stretching vibrations appeared at 2920 and $2840 \mathrm{~cm}^{-1}$, which were attributed to the methylene group of the dodecyl moiety. The above results demonstrated adequately that the grafting of DG onto the surface of jute fabrics by $\mathrm{HRP} / \mathrm{H}_{2} \mathrm{O}_{2} / \mathrm{ACAC}$ system was successful.

\section{XPS Analysis of Jute Fabrics}

The surface composition of jute fabrics was analyzed by XPS. The results (Table 2) showed an increase in the $\mathrm{C} / \mathrm{O}$ ratio from $1.470(\mathrm{HRP} / \mathrm{DG})$ to $1.614\left(\mathrm{HRP} / \mathrm{H}_{2} \mathrm{O}_{2} / \mathrm{DG}\right)$. DG has a high carbon to oxygen content ratio (2.85) [31]. Hence, the increase in carbon content of in the case of $\mathrm{HRP} / \mathrm{H}_{2} \mathrm{O}_{2} / \mathrm{DG}$ could be explained by the coupling of DG to jute surfaces. Compared with the control (DG alone-treated jute), the $\mathrm{C} / \mathrm{O}$ ratio of the $\mathrm{HRP} / \mathrm{DG}$ or $\mathrm{H}_{2} \mathrm{O}_{2} / \mathrm{DG}$-treated jute also increased due to adsorption of tiny amounts of DG, which was less remarkable than that of the $\mathrm{HRP} / \mathrm{H}_{2} \mathrm{O}_{2} / \mathrm{DG}$-treated sample, relative to the control. These results clearly demonstrated that the grafting of DG onto the surface of jute fabrics indeed occurred and the $\mathrm{HRP} / \mathrm{H}_{2} \mathrm{O}_{2} / \mathrm{DG}$ treated jute surface contained not only adsorbed DG but also grafted DG. In addition, an increase of the nitrogen content in HRP-treated samples could be due to the adsorption of some enzyme proteins. However, the adsorption of the enzyme on the $\mathrm{HRP} / \mathrm{H}_{2} \mathrm{O}_{2} /$ DG-treated jute surface was probably suppressed, due to the incorporation of the hydrophobic DG, which showed up in the form of a decrease in nitrogen content from $2.78 \%$ to $2.76 \%$.

\section{SEM Analysis of Jute Fabrics}

Figure 5 shows the changes in surface morphologies ( $3.00 \mathrm{k}$ magnification) of differently treated jute fibers by SEM. It showed that the four types of jute fibers exhibited different structures. The surfaces of the ungrafted jute fibers were smooth, tidy, and neatly arranged with few impurities on their surfaces (Fig. 5a, b, c), especially in the case of DG alone-treated sample. However, there still existed some small flakes which were attributed to the non-specific adsorption of DG. After treatment with $\mathrm{HRP} / \mathrm{H}_{2} \mathrm{O}_{2} / \mathrm{DG}$, the

Table 2 XPS analysis of jute fabric surfaces after various treatments

\begin{tabular}{|c|c|c|c|c|}
\hline Sample & $\mathrm{C}(\%)$ & $\mathrm{O}(\%)$ & $\mathrm{N}(\%)$ & $\mathrm{C} / \mathrm{O}$ \\
\hline $\mathrm{HRP} / \mathrm{H}_{2} \mathrm{O}_{2} / \mathrm{DG}$ & 56.28 & 34.88 & 2.76 & 1.614 \\
\hline $\mathrm{HRP} / \mathrm{DG}$ & 53.48 & 36.39 & 2.78 & 1.470 \\
\hline $\mathrm{H}_{2} \mathrm{O}_{2} / \mathrm{DG}$ & 54.21 & 36.26 & 2.36 & 1.495 \\
\hline DG alone & 50.10 & 39.47 & 2.01 & 1.269 \\
\hline
\end{tabular}



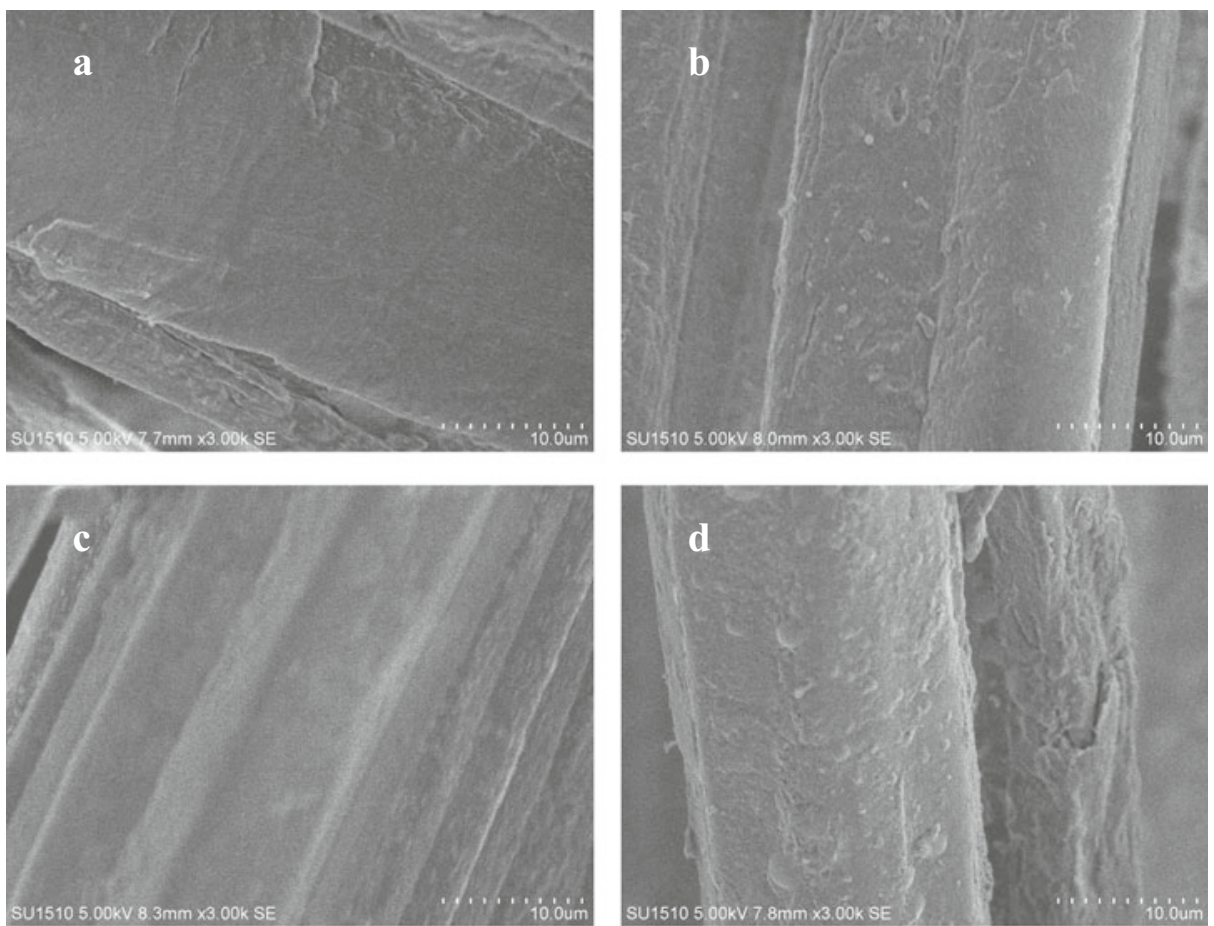

Fig. 5 Surface morphology change of treated jute fibers. a The HRP/DG-treated jute, $\mathbf{b}$ the $\mathrm{H}_{2} \mathrm{O}_{2} / \mathrm{DG}$-treated jute, $\mathbf{c}$ DG alone-treated jute, $\mathbf{d}$ the $\mathrm{HRP} / \mathrm{H}_{2} \mathrm{O}_{2} /$ DG-tread jute

surface of jute fiber became rough and irregular with some multispike-like particles attached to it (Fig. 5d). Since these particles are seen on the surface of the $\mathrm{HRP} / \mathrm{H}_{2} \mathrm{O}_{2} /$ DG-treated jute, they could possibly be regarded as the result of a coating of adsorbed and grafted DG. The SEM microphotographs clearly demonstrated the attachment of DG on the surface of jute fibers by HRP-mediated grafting.

Moreover, the grafted jute fibers exhibited porous structures, which appeared damaged. For instance, the surface of the $\mathrm{H}_{2} \mathrm{O}_{2}$-untreated fibers had a smooth, complete, and compact structure (Fig. 5a, c). In contrast, the surface of the $\mathrm{H}_{2} \mathrm{O}_{2}$-treated fibers showed a rough, damaged-like, and slightly loosened structure with small pores (Fig. 5b, d). The damaged-like porous structures of the grafted jute fibers were probably influenced by the $\mathrm{H}_{2} \mathrm{O}_{2}$ concentration.

\section{Thermal Analysis of Jute Fabrics}

The thermal stabilities of the samples were examined by non-isothermal thermogravimetry. The TGA (in $\mathrm{wt} \%$ ) and derivative thermogravimetric analysis (DTG) (in $\mathrm{wt}^{\%} /{ }^{\circ} \mathrm{C}$ ) curves obtained for the $\mathrm{DG}, \mathrm{DG}$ alone-treated, and grafted jute fabrics are shown in Fig. 6.

Figure 6a shows that DG started to decompose at a low temperature $\left(187.92{ }^{\circ} \mathrm{C}\right)$, and the main weight loss of DG ended at $367.08{ }^{\circ} \mathrm{C}$, which demonstrated that the heat resistance of DG was not good. The loss of absorbed water occurred during the 


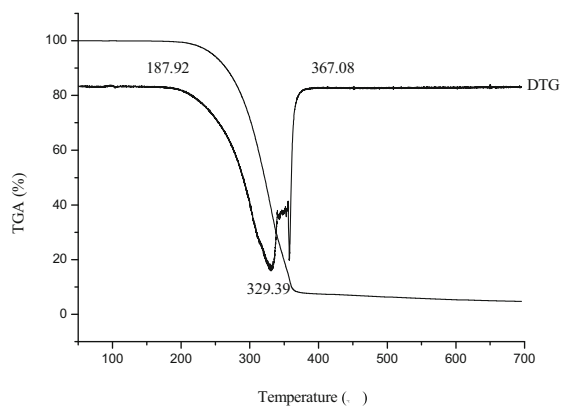

(a)

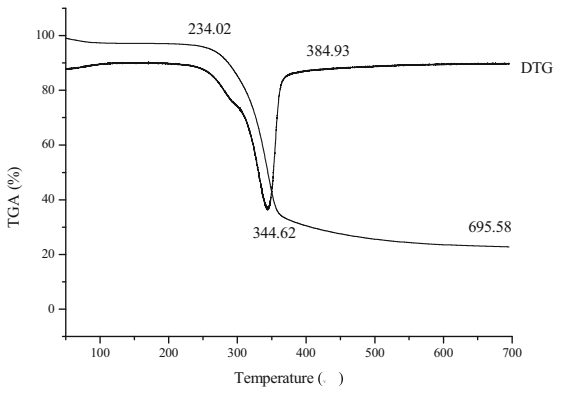

(b)

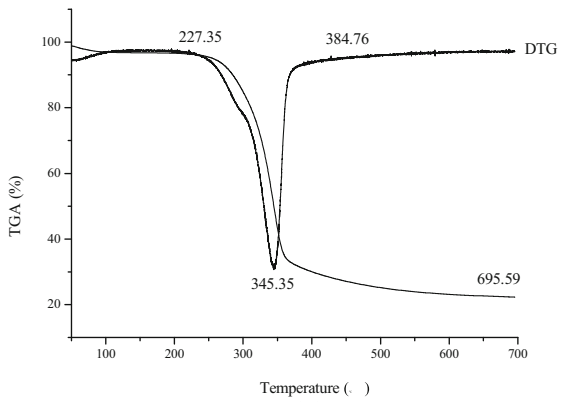

(c)

Fig. 6 TGA and DTG curves for the DG (a), the DG alone-treated jute (b), and the grafted jute (c)

first small stage of weight loss, as observed in Fig. 6b, c. The grafted jute fabrics began decomposing at $227.35{ }^{\circ} \mathrm{C}$, representing a decrease of $6.67{ }^{\circ} \mathrm{C}$, compared to that of the DG alone-treated jute $\left(234.02{ }^{\circ} \mathrm{C}\right)$. The results were consistent with the study of Džunuzović et al. [32], according to which, a weight loss proportional to the weight of surface-grafted gallates occurred between 210 and $800{ }^{\circ} \mathrm{C}$. The maximum rate of mass loss of the grafted jute was $-1.33 \mathrm{wt} \% /{ }^{\circ} \mathrm{C}$ at $345.35{ }^{\circ} \mathrm{C}$, which was almost the same as the result of the $\mathrm{DG}$ alone-treated jute $\left(344.62{ }^{\circ} \mathrm{C}\right.$ with a maximum rate of mass loss of $-1.34 \mathrm{wt} \% /{ }^{\circ} \mathrm{C}$ ). In case of grafted jute, there was solid residue of $22.32 \%$ left over, even at $695.59{ }^{\circ} \mathrm{C}$. However, in the case of DG alone-treated jute, $22.80 \%$ was left at $695.58{ }^{\circ} \mathrm{C}$.

Besides TGA and DTG, another method, DSC, was employed to study the degradation behavior of the jute fibers. The DSC curves of the jute samples are shown in Fig. 7. Compared to the endothermic peak of the DG alone-treated jute $\left(108.42{ }^{\circ} \mathrm{C}\right)$, the grafted jute showed a peak at a higher temperature of $118.82{ }^{\circ} \mathrm{C}$. This difference was an indication of a lesser number of free water molecules (moisture) present in grafted jute, due to the introduction of hydrophobic $-\mathrm{COOCH}_{2}\left(\mathrm{CH}_{2}\right)_{10} \mathrm{CH}_{3}$ chains. The DSC profiles of the grafted jute showed a broad endothermic peak at $325.99{ }^{\circ} \mathrm{C}$ and a broad exothermic peak at $307.96{ }^{\circ} \mathrm{C}$. However, the DSC curve of the DG alone-treated jute sample showed these corresponding peaks at 328.30 and $309.91{ }^{\circ} \mathrm{C}$. In addition to the above peaks, the two samples showed a sharp exothermic peak at the same temperature $\left(370.30{ }^{\circ} \mathrm{C}\right)$. In conclusion, the thermostabilities of the DG alone treated jute and grafted jute did not differ much, with the introduction of DG. 


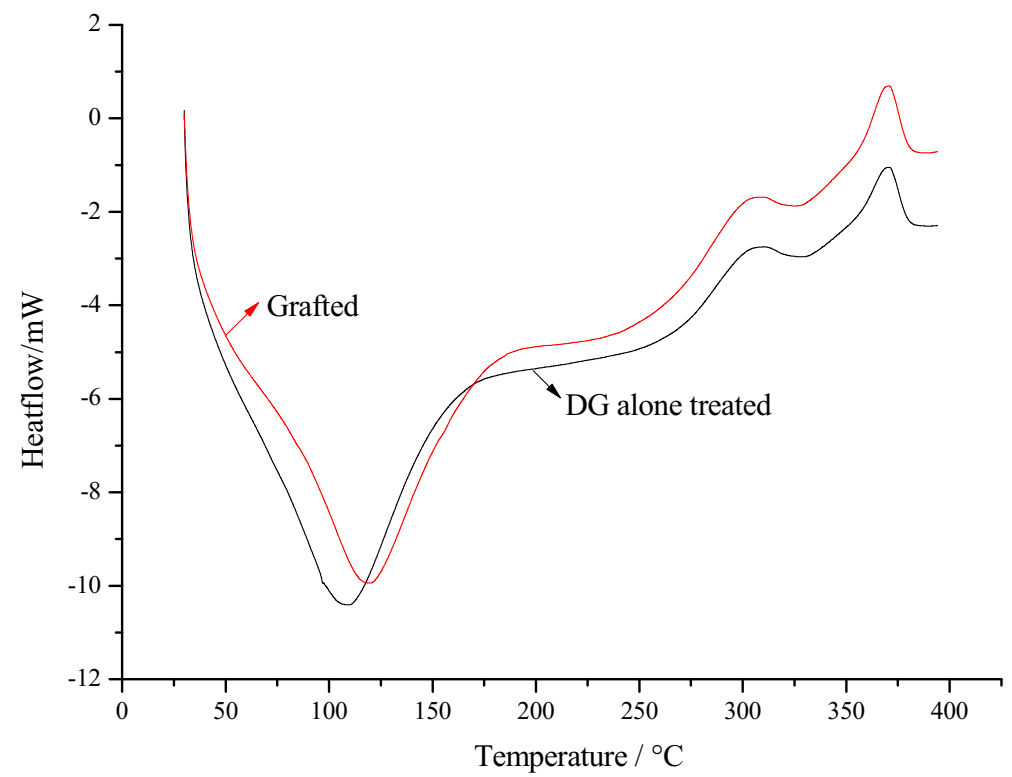

Fig. 7 DSC curves for the DG alone-treated jute and grafted jute

\section{Optimization of the Enzymatic Grafting Process}

The performance of jute fabrics with grafted DG can be limited by several reaction parameters such as dosages of DG, ethanol, $\mathrm{HRP}$ and $\mathrm{H}_{2} \mathrm{O}_{2}$, incubation temperatures, and incubation periods. Figure $8 \mathrm{a}, \mathrm{b}$ indicated that the grafting percentage increased greatly with the addition of DG or HRP until it reached its maximum value and then decreased. This indicated that an increase in monomer or HRP concentration accelerates the homopolymerization reaction rather than getting further grafted, beyond a certain threshold. This results in a decrease in the grafting yield.

The effect of solvents on the grafting reaction is rather complicated due to its interaction with almost every element in the reaction media. The effect of solvent (ethanol) quantities on grafting yields is shown in Fig. 8c. The grafting yield increased by increasing ethanol quantity, attaining a maximum value at about $15 \%$ ethanol concentration and then decreased again. The reason for this declining trend may be the decrease in the catalytic activity of enzyme at a high non-aqueous solvent concentrations $[33,34]$ or due to the fact that an increasing organic concentration changes the partitioning of the substrate between the solvent and the enzyme active site.

Referring to the curve for $\mathrm{H}_{2} \mathrm{O}_{2}$ concentration (Fig. 8d), the grafting percentage decreased with increasing $\mathrm{H}_{2} \mathrm{O}_{2}$ concentration, due to degradation of $\mathrm{HRP}$ by $\mathrm{H}_{2} \mathrm{O}_{2}$, which decreased the catalytic activity of the enzyme [35]. The effect of temperature on the enzyme catalyzed grafting (Fig. 8e) corresponded roughly to the HRP activity. The grafting percentage was greatly increased with increase in incubation period and then decreased (Fig. 8f). This phenomenon may be explained by the slow decay of the enzyme activity [36]. Based on the results obtained by analyzing Fig. 8, the optimum process conditions for jute fabrics grafted DG should include an incubation of jute fabric in $50-\mathrm{mL}$ ethanol/buffer $(0.1 \mathrm{M}, \mathrm{pH} 7.0)$ reaction solution with $10 \mathrm{mmol} / \mathrm{L} \mathrm{DG}, 15 \%(v /$ v) ethanol, $1.0 \mathrm{~mL} \mathrm{HRP}$, and $0.75 \mathrm{~mL} \mathrm{H}_{2} \mathrm{O}_{2}$ at $50{ }^{\circ} \mathrm{C}$ for $4 \mathrm{~h}$. 


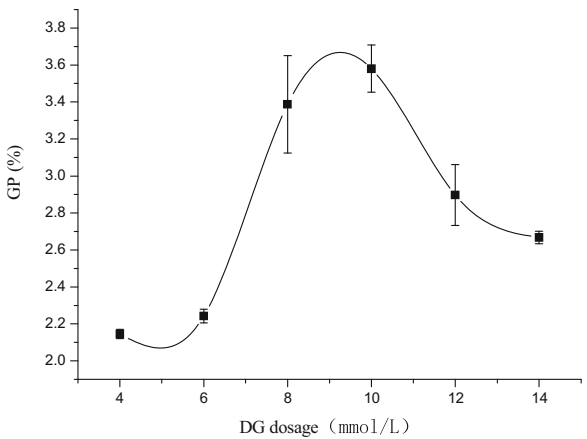

(a)

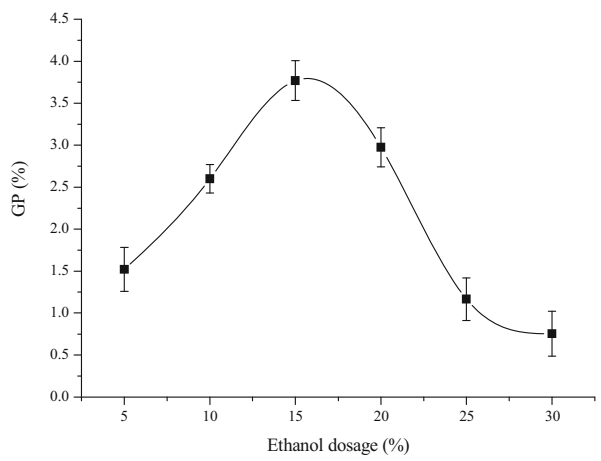

(c)

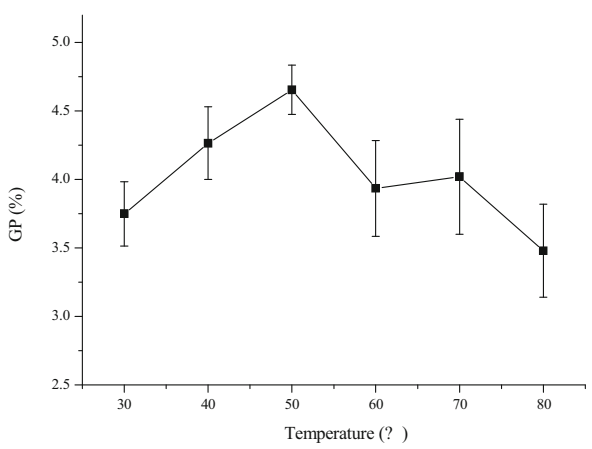

(e)

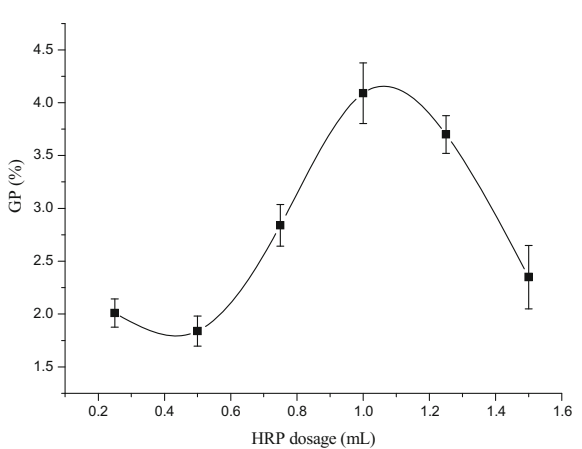

(b)

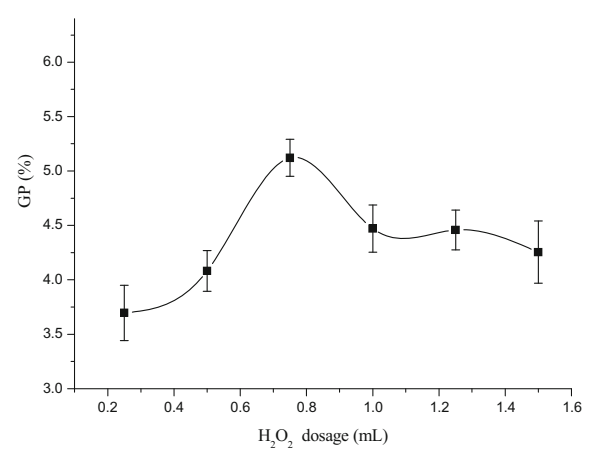

(d)

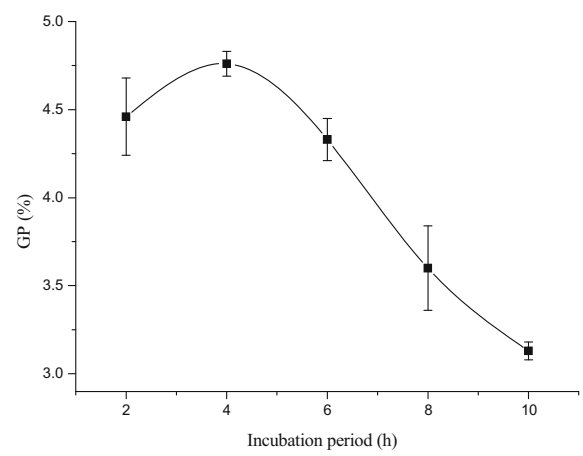

(f)

Fig. 8 Optimization of the process parameters. a Dosage of DG, $\mathbf{b}$ dosage of HRP, $\mathbf{c}$ dosage of ethanol, $\mathbf{d}$ dosage of $\mathrm{H}_{2} \mathrm{O}_{2}$, e incubation temperature, and $\mathbf{f}$ incubation time

\section{Effect of DG Grafting on Hydrophobicity of Jute Fabric}

The surface hydrophobicity of the DG-grafted jute fabric, which was modified using the abovementioned optimized reaction conditions, was investigated in terms of water contact angle and wetting time. The jute fabrics treated with DG alone, HRP/DG, and 
Table 3 The hydrophobicity of the jute fiber

\begin{tabular}{lll}
\hline Treatment & Wetting time & Contact angle $\left(^{\circ}\right)$ \\
\hline DG alone & $<1 \mathrm{~s}$ & 0 \\
$\mathrm{HRP} / \mathrm{DG}$ & $<1 \mathrm{~s}$ & 0 \\
$\mathrm{H}_{2} \mathrm{O}_{2} / \mathrm{DG}$ & $<1 \mathrm{~s}$ & 0 \\
$\mathrm{HRP} / \mathrm{H}_{2} \mathrm{O}_{2} /$ DG & $>30 \mathrm{~min}$ & $123.68 \pm 3.21$ \\
\hline
\end{tabular}

$\mathrm{H}_{2} \mathrm{O}_{2} /$ DG were used as control samples, and the same stoichiometries of reagents were maintained as those used for preparing the DG-grafted samples. As shown in Table 3, the water contact angle of the DG-grafted jute fabric $\left(123.68^{\circ}\right)$ was obviously larger compared to the three ungrafted jute fabrics $\left(\sim 0^{\circ}\right)$ and gradually decreased with increasing time (Fig. 9). Moreover, the wetting time of the grafted jute fabrics, prepared by using the $\mathrm{HRP} / \mathrm{H}_{2} \mathrm{O}_{2}$ catalyzed system, was also distinctly higher than the other three samples, which was consistent with the water contact angle measurement.

In conclusion, the wetting time and contact angle of the grafted jute fiber were more than $30 \mathrm{~min}$ and $123.68^{\circ}$, respectively, which were clearly much better than the others. These findings indicated that the hydrophobicity of the jute fibers was enhanced after grafting of $\mathrm{DG}$, due to introduction of the hydrophobic group $\mathrm{COO}\left(\mathrm{CH}_{2}\right)_{11} \mathrm{CH}_{3}$.

\section{Analysis of Jute Fabric/PP Composites}

The breaking strengths of PP composites reinforced by DG-grafted jute fabrics, which were prepared by the abovementioned optimized grafting conditions, are shown in Table 4. Compared to the ungrafted jute/PP composite, the grafted jute fabric reinforced composites showed a high breaking strength, i.e., higher values of Young's

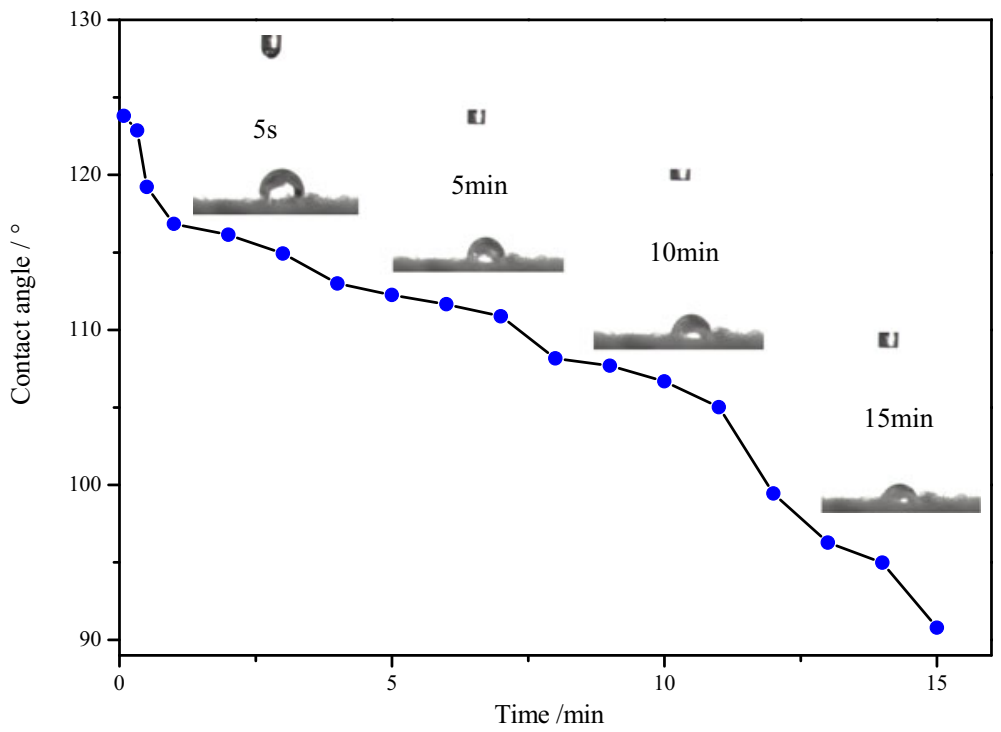

Fig. 9 The water contact angle of the DG-grafted jute fabrics 
Table 4 The breaking strength of polypropylene (PP) composites reinforced by ungrafted jute fabric and DG-grafted jute fabric

\begin{tabular}{llll}
\hline Sample & $\begin{array}{l}\text { Young's } \\
\text { modulus }(\mathrm{GPa})\end{array}$ & $\begin{array}{l}\text { Stress } \\
(\mathrm{M} \mathrm{Pa})\end{array}$ & Strain (\%) \\
\hline Ungrafted & $1.52 \pm 0.11$ & $30.24 \pm 6.71$ & $8.69 \pm 0.20$ \\
DG-grafted & $1.64 \pm 0.23$ & $53.79 \pm 5.83$ & $9.10 \pm 0.52$ \\
\hline
\end{tabular}

modulus, stress, and strain which increase by $7.9,78$, and $4.7 \%$, respectively. There was a large increase in breaking stress relative to the control in comparison with other surface modification methods. For instance, the stress of maleic anhydride-grafted jute/polypropylene (MAPP) was $48 \%$ greater than that of the untreated jute/PP composite, with fiber content of $38 \mathrm{wt} \%$ [37]. Hong et al. [17] found an increase in tensile stress of about $16 \%$ for silanized jute/PP composites containing $1 \mathrm{wt} \%$ jute. A maximum increase in tensile strength of $58 \%$ was obtained for $10 \mathrm{wt} \% \mathrm{G} 3003$ coupling agent (MAPP)-modified PP matrix composites with $30 \mathrm{wt} \%$ of flax fiber bundle [38].

These improved properties are a result of increased hydrophobicity and good interfacial compatibility of the jute fibers with the PP resin. The results are in agreement with the hydrophobicity of the tested jute fabrics, as seen in Table 3. The changes in the breaking strength were an indication of improved compatibility between the jute fiber and PP after surface hydrophobization by grafting of DG molecules.

The interfacial compatibility can be largely influenced by the polarity of the two materials forming the interface. The lesser the difference in polarities of the materials, the better would be the compatibility at the interface. The surface hydrophobization of the jute fabric could fulfill the requirement of the compatibility with hydrophobic resins to prepare fiber-reinforced composites of high performance.

\section{Conclusions}

In this study, modification of jute fabrics by grafting reactions was performed using DG monomer and HRP catalyst. The initiation system of $\mathrm{HRP} / \mathrm{H}_{2} \mathrm{O}_{2} / \mathrm{ACAC}$ could start the copolymerization of PG and MP (the model compounds of DG and lignin, respectively), which was proved by MALDI-TOF MS. HRP played the role of a catalyst in the reaction medium and was essential for the initiation of the free-radical polymerization reaction. The characteristic absorption peaks due to $\mathrm{C}=\mathrm{O}$ vibration, $\mathrm{C}-\mathrm{H}$ vibration, and $\mathrm{O}-\mathrm{H}$ vibration, shown in the FTIR-ATR spectrum, the increasing value of $\mathrm{C} / \mathrm{O}$ in XPS test, and the appearance of the grafted jute fibers as rough surfaces in the SEM image as well as a little decrease in the thermal stability, as tested by TGA, DTG, and DSC, confirm that DG was grafted onto the surface of jute fabrics, along with the introduction of the hydrophobic $-\mathrm{COO}\left(\mathrm{CH}_{2}\right)_{11} \mathrm{CH}_{3}$ group. The desired hydrophobicity obtained was tested by wetting time and water contact angle measurements. The value of tensile stress of DG-grafted jute/PP composite also showed an increase, which was greater than other surface modification methods, due to the high hydrophobicity and good interfacial compatibility of the jute fibers with the PP resin. 
Acknowledgments This work was financially supported by the National Natural Science Foundation of China (51173071), the Program for New Century Excellent Talents in University (NCET-12-0883), Program for Changjiang Scholars and Innovative Research Team in University (No. IRT 15R26) the Fundamental Research Funds for the Central Universities (JUSRP51312B, JUSRP51505), and the Graduate Student Innovation Plan of Jiangsu Province of China (SJLX_0527).

\section{References}

1. Zini, E., \& Scandola, M. (2011). Green composites: an overview. Polymer Composites, 32, 1905-1915.

2. Ashori, A. (2008). Wood-plastic composites as promising green-composites for automotive industries. Bioresource Technology, 99, 4661-4667.

3. Lo Re, G., Morreale, M., Scaffaro, R., \& La Mantia, F. P. (2012). Kenaf-filled biodegradable composites: rheological and mechanical behaviour. Polymer International, 61, 1542-1548.

4. Sait, A. O. A. S., \& Subramaniam, V. (2014). Composites from natural fibres. International Journal of Engineering \& Technolog, 3, 14-16.

5. Li, Z., Renneckar, S., \& Barone, J. R. (2010). Nanocomposites prepared by in situ enzymatic polymerization of phenol with TEMPO-oxidized nanocellulose. Cellulose, 17, 57-68.

6. Lin, Z. Y., \& Renneckar, S. (2011). Nanocomposite-based lignocellulosic fibers 2: layer-by-layer modification of wood fibers for reinforcement in thermoplastic composites. Composites Part A: Applied Science, 42, 84-91.

7. Dong, A. X., Yu, Y. Y., Yuan, J. G., Wang, Q., \& Fan, X. R. (2014). Hydrophobic modification of jute fiber used for composite reinforcement via laccase-mediated grafting. Applied Surface Science, 301, 418-427.

8. Uawongsuwan, P., Yang, Y. Q., \& Hamada, H. (2015). Long jute fiber-reinforced polypropylene composite: effects of jute fiber bundle and glass fiber hybridization. Journal of Applied Polymer Science, 132, 41819-41831.

9. Padal, K. T. B., Ramji, K., \& Prasad, V. V. S. (2014). Thermal properties of jute nanofibre reinforced composites. International Journal of Engineering Research, 3, 333-335.

10. Arbelaiz, A., Fernandez, B., Valea, A., \& Mondragon, I. (2006). Mechanical properties of short flax fibre bundle/poly (-caprolactone) composites: influence of matrix modification and fibre content. Carbohydrate Polymers, 64, 224-232.

11. Rong, M. Z., Zhang, M. Q., Liu, Y., Yang, G. C., \& Zeng, H. M. (2001). The effect of fiber treatment on the mechanical properties of unidirectional sisal-reinforced epoxy composites. Composites Science and Technology, 61, 1437-1447.

12. Lei, W., \& Zhang, C. S. (2008). The mechanics performance of ramie fabric/polypropylene composites. Journal of Composite Materials, 25, 40-45.

13. Marais, S., Gouanve, F., Bonnesoeur, A., Greneta, J., Poncin-Epaillardb, F., Morvanc, C., \& Métayer, M. (2005). Unsaturated polyester composites reinforced with flax fibers: effect of cold plasma and antoclave treatments on mechanical and permeation properties. Composites: Part A, 36, 975-986.

14. Albanoa, C., Reyes, J., Ichazo, M., Gonzálezc, J., Britob, M., \& Moronta, D. (2002). Analysis of the mechanical, thermal and morphological behaviour of polypropylene compounds with sisal fibre and wood flour irradiated with gamma rays. Polymer Degradation and Stability, 76, 191-203.

15. Zhang, Y. F., Zhang, C. A., Xiao, J. Y., Zeng, J. C., Liu, J., Du, G., \& Wang, C. Q. (2002). Study on graft copolymerization of ramie noil fiber and MMA. Materials Science and Engineering, 20, 527-529.

16. Zhang, C. A., Lu, B., Zeng, J. C., \& Zhang, Y. F. (2004). Surface treatment of fallen ramie and study on properties of composites. Engineering Plastics Application, 32, 5-9.

17. Hong, C. K., Hwang, I., Kim, N., Park, D. H., Hwang, B. S., \& Nah, C. (2008). Mechanical properties of silanized jute-polypropylene composites. Journal of Industrial and Engineering Chemistry, 14, 71-76.

18. Kohri, M., Fukushima, H., Taniguchi, T., \& Nakahira, T. (2010). Synthesis of polyarbutin by oxidative polymerization using PEGylated hematin as a biomimetic catalyst. Polymer Journal, 42, 952-955.

19. Cheng, W. J., \& Harper, W. F., Jr. (2012). Chemical kinetics and interactions involved in horseradish peroxidase-mediated oxidative polymerization of phenolic compounds. Enzyme and Microbial Technology, 50, 204-208

20. Hollmann, F., \& Arends, I. W. C. E. (2012). Enzyme initiated radical polymerizations. Polymers, 4, 759-766.

21. del Río, J. C., Rencoret, J., Marques, G., Li, J., Gellerstedt, G., Jiménez-Barbero, J., Martínez, A. T., \& Gutiérrez, A. (2009). Structural characterization of the lignin from jute (Corchorus capsularis) fibers. Journal of Agricultural and Food Chemistry, 57, 10271-10281.

22. Liu, H., Yang, F. K., \& Qiu, L. H. (2001). Study on polymerization of lignin-phenol resin catalyzed by horseradish peroxidase. Polymeric Materials Science and Engineering, 17, 173-175. 
23. Gao, G. Z., Karaaslan, M. A., Kadla, J. F., \& Ko, F. (2014). Enzymatic synthesis of ionic responsive lignin nanofibres through surface poly(N-isopropylacrylamide) immobilization. Green Chemistry, 16, 3890-3898.

24. Liu, R. R., Dong, A. X., Fan, X. R., Wang, Q., Yu, Y. Y., \& Cavaco-Paulo, A. (2015). HRP-mediated polyacrylamide graft modification of raw jute fabric. Journal of Molecular Catalysis B: Enzymatic, 116, 2938.

25. Saastamoinen, P., Mattinen, M. L., Hippi, U., Nousiainen, P., Sipilä, J., Lille, M., Suurnäkki, A., \& Pere, J. (2012). Laccase aided modification of nanofibrillated cellulose with dodecyl gallate. Bioresources, 7, 57495770 .

26. Mattinen, M. L., Maijala, P., Nousiainen, P., Smeds, A., Kontro, J., Sipilä, J., Tamminen, T., Willför, S., \& Viikari, L. (2011). Oxidation of lignans and lignin model compounds by laccase in aqueous solvent systems. Journal of Molecular Catalysis B: Enzymatic, 72, 122-129.

27. Kobayashi, S., \& Makino, A. (2009). Enzymatic polymer synthesis: an opportunity for green polymer chemistry. Chemical Reviews, 109, 5288-5353.

28. Faix, O. (1991). Classification of lignins from different botanical origins by FT-IR spectroscopy. Holzforschung, 45, 21-27.

29. Vachouda, L., Chen, T. H., Payne, G. F., \& Vazquez-Duhalt, R. (2001). Peroxidase catalyzed grafting of gallate esters onto the polysaccharide chitosan. Enzyme and Microbial Technology, 29, 380-385.

30. Zavaleta-Avejar, L., Bosquez-Molina, E., Gimeno, M., Pérez-Orozco, J. P., \& Shirai, K. (2014). Rheological and antioxidant power studies of enzymatically grafted chitosan with a hydrophobic alkyl side chain. Food Hydrocolloid., 39, 113-119.

31. Hossain, K. M. G., González, M. D., Monmany, J. M. D., \& Tzanov, T. (2010). Effects of alkyl chain lengths of gallates upon enzymatic wool functionalisation. Journal of Molecular Catalysis B: Enzymatic, 67, 231235.

32. Džunuzović, E. S., Džunuzović, J. V., Marinković, A. D., Marinović-Cincović, M. T., Jeremić, K. B., \& Nedeljković, J. M. (2012). Influence of surface modified $\mathrm{TiO}_{2}$ nanoparticles by gallates on the properties of PMMA/ $\mathrm{TiO}_{2}$ nanocomposites. European Polymer Journal, 48, 1385-1393.

33. Akkara, J. A., Ayyagari, M. S. R., \& Bruno, F. F. (1999). Enzymatic synthesis and modification of polymers in nonaqueous solvents. Trends in Biotechnology, 17, 67-73.

34. Premachandran, R. S., Banerjee, S., Wu, X. K., John, V. T., McPherson, G. L., Akkara, J., Ayyagari, M., \& Kaplan, D. (1996). Enzymatic synthesis of fluorescent naphthol-based polymers. Macromolecules, 29, 6452-6460.

35. Durand, A., Lalot, T., Brigodiot, M., \& Maréchal, E. (2000). Enzyme-mediated initiation of acrylamide polymerization; reaction mechanism. Polymer, 41, 8183-8192.

36. Battistel, E., Morra, M., \& Marinetti, M. (2001). Enzymatic surface modification of acrylonitrile fibers. Applied Surface Science, 177, 32-41.

37. Liu, X. Y., \& Dai, G. C. (2007). Surface modification and micromechanical properties of jute fiber mat reinforced polypropylene composites. Express Polymer Letters, 5, 299-307.

38. Arbelaiz, A., Fernandez, B., Ramos, J. A., Retegi, A., Llano-Ponte, R., \& Mondragon, I. (2005). Mechanical properties of short flax fibre bundle/polypropylene composites: influence of matrix/fibre modification, fibre content, water uptake and recycling. Composites Science and Technology, 65, 1582-1592. 